\title{
Núcleos urbanos consolidados en proceso de abandono. EI caso del Centro Histórico de Quito
}

\author{
Gabriela Naranjo Serrano ${ }^{1}$, Rafael Trujillo Rodríguez ${ }^{2}$, \\ Melissa Velástegui Ricaurte ${ }^{3}$
}

Facultad de Arquitectura, Diseño y Artes, Pontificia Universidad Católica del Ecuador.

E-mail: ${ }^{1}$ mgnaranjo@puce.edu.ec, ${ }^{2}$ rafael.ant.trujillo@gmail.com, ${ }^{3}$ meli-vr@hotmail.es

\begin{abstract}
Resumen. El objeto de este artículo es estudiar el abandono del centro histórico de Quito (CHQ). Este territorio, que posee características sociales, culturales, naturales y patrimoniales únicas, ha entrado en un proceso de decrecimiento demográfico, contrario a la tendencia de la urbe, a pesar de ser una de las zonas más compactas y con mayor consolidación urbana en la ciudad.

La historia demuestra que este proceso no siempre fue así. Por el contrario, los barrios que conforman el CHQ se mantuvieron, por mucho tiempo, como los más poblados de la ciudad. Sin embargo, entrada la década de los 70 s y con un nuevo modelo de planificación urbana, cambió radicalmente la dinámica del sector. Los procesos urbanos y la transformación socio-económica han propiciado un decrecimiento poblacional, aún cuando la capacidad residencial es sumamente alta. Esto, a su vez, ha provocando la subutilización de suelo urbano, reemplazando usos formales por otros informales y de bajo impacto. En este artículo se presenta, en primera instancia, un estudio comparativo del proceso evolutivo de la mancha urbana de Quito contrastado con los índices de incremento demográfico. A continuación, se realiza un análisis de las posibles causas que han obligado a los habitantes del CHQ a abandonarlo y, finalmente, se proponen algunas estrategias para revertir este proceso.
\end{abstract}

Palabras clave: Centros históricos, Quito, ciudad compacta, núcleos consolidados, abandono, despoblamiento, consolidación

\section{Antecedentes}

Las grandes ciudades actualmente se encuentran en continuo crecimiento, sin embargo, muchas de ellas han presentado una clara dispersión en sus núcleos consolidados, los cuales se deslindan de este constante proceso, presentando una problemática de abandono.

Los centros históricos latinoamericanos han sido considerados como espacios distintivos de las ciudades por sus cualidades simbólicas, su carácter y memoria, manifestando el desarrollo urbano de las ciudades; no obstante, muchos de estos han presentado un fenómeno de abandono, como es el caso del Centro Histórico de Quito (CHQ).
E1 Distrito Metropolitano de Quito (DMQ) nace de un núcleo central (CHQ). Su área urbana consolidada ha presentado un crecimiento territorial evidente a partir del año 1760 hasta la actualidad, que, por su geografía y morfología, se ha dado de manera longitudinal, modificando la implantación original de la ciudad de Quito. A través de conurbaciones, la ciudad ha sobrepasado los límites naturales y ha ocupado parroquias rurales de los valles adyacentes conformando la estructura metropolitana de Quito (Municipio del Distrito Metropolitano de Quito, 2015).

Durante el período de consolidación del DMQ, 1970, existen procesos migratorios que dan lugar a un crecimiento territorial indiscutible, sin embargo, también se produce 
un claro desplazamiento de la población del área urbana hacia el área rural. De esta manera, según el censo de 1990, el 81\% de las viviendas se ubicaban en el área urbana y el 19\% en el área rural (Instituto Nacional de Estadísticas y Censos, 2008). Para el último censo en el año 2010, la modalidad de ocupación cambia y el incremento relativo de las viviendas en las parroquias urbanas corresponde al $29 \%$ frente a un incremento en el área rural del 63\%.

Durante el período inter-censal 1990-2001, Quito urbano ha presentado un incremento poblacional correspondiente al $26.4 \%$ y una tasa de crecimiento de $2.2 \%$. Para el año 2010 se da un incremento poblacional del $15.1 \%$ así como una tasa de crecimiento del 1.6\% (Municipio del Distrito Metropolitano de Quito, 2015). Los indicadores del DMQ señalan que entre los años 2001 y 2010, la tasa de crecimiento en las zonas rurales (4\%) ha superado en gran medida a la correspondiente el área urbana.

La densidad poblacional del DMQ es de 42.7 habitantes/hectárea (INEC,2010), mostrando una clara dispersión de los habitantes a través del territorio, de esta manera se evidencia la expansión geográfica desordenada de la ciudad, lo cual a su vez genera un: "alto grado de inequidad de servicios, áreas verdes e infraestructuras, una movilidad poco eficiente, $\mathrm{y}$ condiciones tanto económicas como ambientales desfavorables para la calidad de vida de sus habitantes" (Municipio del Distrito Metropolitano de Quito, 2015). Las parroquias urbanas, como la Mariscal Sucre, Chimbacalle y Centro Histórico de Quito, se han visto afectadas debido a dichos factores, presentando una densidad poblacional menor en el último período inter-censal (Secretaría de Territorio Hábitat y Vivienda, 2012), sus habitantes se desplazan, migrando a zonas rurales, ocupando espacios suburbanos, que satisfagan sus necesidades, generándose un proceso de abandono.

Actaulmente, el CHQ se presenta como un espacio consolidado. Los recursos de este sector abastecen en gran proporción al turista, dejando de lado a los habitantes del lugar. El incremento de viviendas abandonadas o subutilizadas, el cambio del uso de suelo de las viviendas, la disminución poblacional, el déficit de oportunidades, la alta concentración de grupos vulnerables con escasos recursos económicos, el crecimiento bilateral Norte-Sur de la ciudad, el déficit de elementos cotidianos y la falta de comprensión de características urbanas han causado que gran parte de los habitantes presenten un continuo abandono del lugar (Ministerio de Desarrollo Urbano y Vivienda, 2012).

A pesar de los procesos de consolidación y desarrollo que se han dado a través de los años para revitalizar el CHQ, las innumerables problemáticas sociales, culturales, ambientales y estructurales como los índices altos de delincuencia, inseguridad y pobreza, dificultad de accesibilidad y movilidad, deterioro espacial y de los bienes patrimoniales, una condición ambiental degradante, déficit de infraestructura y servicios públicos, grandes equipamientos y espacios públicos que resultan incompatibles con los residentes del sector, son factores a tomar en cuenta para una intervención integral en el sector (Ministerio de Desarrollo Urbano y Vivienda, 2015)

En un primer momento se encuentra la fundación misma de la ciudad de Quito en 1534, en la época de la conquista. Aquí se define el espacio central de la ciudad que crecerá en forma de damero y a través de dos ejes perpendiculares: norte-sur y este-oeste, situando en el centro de estos a la Plaza Grande, alrededor de la cual se situarán los diferentes poderes del estado: político, legislativo y religioso.

En un segundo momento, alrededor de dicha plaza, se inicia la construcción de grandes residencias destinadas a las clases más acomodadas de la población. Los modos de estructura social se evidenciaron en la manera de ocuparlas, aunque en la misma vivienda habitasen tanto los dueños como los sirvientes, estos últimos ocupaban los pisos más bajos y las partes traseras ya que las condiciones externas en cuanto higiene y salubridad eran bastante degradadas. Así mismo, una estratificación en pisos pretendía impedir el contacto entre españoles y mestizos o indígenas. Para este momento se logra la consolidación de la zona central gracias a la clara definición de la zona administrativa, de comercios y de vivienda de clase alta.

Desde fines de siglo XVIII hasta principios 


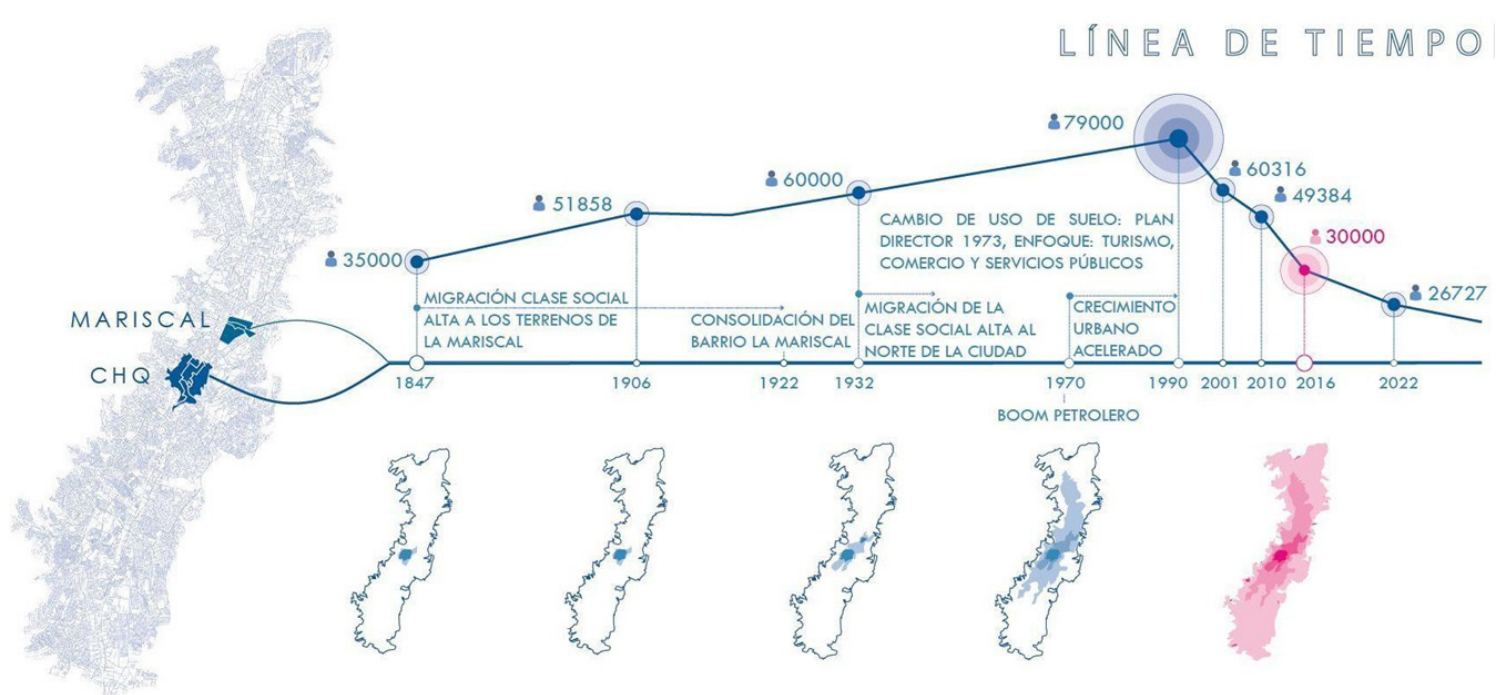

Fig. 1. Línea de tiempo crecimiento poblacional de Quito. (Fuente: Rafael Trujillo, 2016)

del siglo pasado el CHQ no sufre mayores modificaciones.

A partir de un tercer momento, en la primera década del siglo $\mathrm{XX}$, la ciudad sufre un cambio decisivo en cuanto su morfología, el crecimiento que se venía realizando de manera radial-concéntrica, empieza ahora a desarrollarse de forma longitudinal (Carrión, 1983) debido a las cordilleras que forman el valle donde se asienta Quito, y a raíz de este crecimiento se marca también una segregación socio espacial, hacia el norte se desplazan las clases de mayor poder económico, mientras que el sur se destina para las clases bajas, esto debido a que en esta zona se ubican las primeras industrias por la llegada del ferrocarril en 1909. En este momento la zona del CHQ mantiene más o menos la estructura social que venía manejando en épocas pasadas.

En la década siguiente, se inicia el proceso de densificación del centro. La alta migración del campo a la ciudad, la salida de los dueños de los edificios hacia la zona norte y la revalorización del suelo urbano llevaron al fenómeno de tugurización del CHQ, en donde, debido a las altas rentas de las edificaciones, los habitantes se ven forzados a compartirlos con varios vecinos, lo que lleva al hacinamiento.

Para 1942 se encarga el plan de desarrollo urbano de Quito al arquitecto Jones Odriozola. Tres años más tarde se expone la zonificación de la propuesta original, con ajustes realizados por la alcaldía. Entre los puntos que afectaban al CHQ se encuentran:

- La zona central se designa como centro cívico del gobierno donde se desempeñan "todas las funciones de administración capitalinas

- La zona comercial y de vivienda media se extiende en algunos barrios y también hacia la zona sur del Panecillo (CHQ)

- Partiendo del punto final de la estación de descarga y de pasajeros del ferrocarril se determina el establecimiento de la industria. En el espacio se establecen las barriadas obreras.

- El lado norte queda establecida toda la zona residencial y la formación de barrios con el concepto de ciudad jardín

Para 1950, la ciudad inició un proceso de desarticulación espacial y de sus elementos, sus límites originales se difuminaron e inició la invasión de laderas aledañas. Se producen cambios a nivel social, los residentes de las clases altas de la zona centro se ven presionadas por las clases populares y medias quienes invaden sus antiguas residencias, esto sumado a la subdivisión de las construcciones por herencias o ventas en partes. De esta forma, las clases altas continúan su traslado hacia el norte. (Achig, 1983)

En la década de los 60s, las grandes ciudades como Guayaquil y Quito, se convierten en centros importantes de acumulación de capital y generadores importantes de actividades económicas. Es así que desde las provincias cercanas y áreas rurales empieza un éxodo 
masivo hacia estas ciudades que han iniciado ya procesos de mejora en varios de los sistemas como los de transporte y comunicación, en los mercados por lo tanto la vida urbana se hace más atractiva. Se consolidan así los fenómenos de tugurización, la expansión urbana, los asentamientos informales en laderas y problemáticas de tipo social como el desempleo y la pobreza. (Carrión, 1983)

En 1978, Quito fue declarada como Patrimonio Cultural de la Humanidad por la UNESCO y a partir de 1981 se proponen una serie de planes urbanos para Quito donde la mayor preocupación está en cómo intervenir el centro, ahora patrimonial.

En 1984 el Instituto Nacional de Patrimonio Cultural del Ecuador declaró al CHQ como bien perteneciente al patrimonio cultural del Estado, y con el posterior terremoto de 1985 se crea el Fondo de Salvamento del Patrimonio Cultural (FONSAL) para proteger y asegurar las construcciones históricas y patrimoniales (Del Pino, 2009)

En la década de los 90s el CHQ experimentó su más alta densidad poblacional, y a partir de su pico más alto comenzó la pérdida de población.

Varios planes especiales se han realizado desde esos años, planes enfocados sobre todo en la renovación de la imagen urbana, acción necesaria ya que a mediados de los 90 s el CHQ se convirtió en la zona que concentraba mayores índices de microtráfico y prostitución. Otros de los énfasis de los planes consistieron en el rescate de los inmuebles patrimoniales y la retirada de comerciantes informales que ocupaban varias calles del CHQ, a todos ellos se los re-localizó en grandes centros comerciales. El último de los planes especiales para esta zona data de hace pocos meses atrás.

\section{Situación actual: \\ Densidad poblacional y abandono del núcleo urbano consolidado}

El CHQ, de manera opuesta al crecimiento demográfico del Distrito, ha ido perdiendo su población. Enel año de 1990 contaba con 79.000 habitantes y para el año 2010 el número de habitantes decrece categóricamente, contando con solo 49.384 habitantes, esto representa a una pérdida de $37.5 \%$ de habitantes en 20 años, si la tendencia continúa, se prevé que para el año 2022 la población se reduzca a 26.727 habitantes en el Centro Histórico de Quito (Secretaría de Territorio Hábitat y Vivienda, 2012).

Los barrios que comprenden el Centro Histórico han presentado diversos índices de abandono y permanencia, desde el año 1990

\begin{tabular}{|l|l|l|l|l|l|}
\hline \multicolumn{1}{|c|}{ Barrio } & $\begin{array}{l}\text { Superficie } \\
\text { (Ha.) }\end{array}$ & $\begin{array}{l}\text { Población } \\
\text { (hab.) }\end{array}$ & $\begin{array}{l}\text { Densidad Poblacional } \\
\text { (hab./Ha. })\end{array}$ & $\begin{array}{l}\text { Permanencia 1990-2010 } \\
(\%)\end{array}$ & $\begin{array}{l}\text { Abandono } \\
\text { 1990-2010 (\%) }\end{array}$ \\
\hline Gonzáles Suárez & 57,68 & 4.134 & 71,7 & 60 & 40 \\
\hline San Roque & 22,28 & 4.768 & 214,0 & 98 & 2 \\
\hline La Loma & 33,14 & 5.002 & 150,9 & 72 & 28 \\
\hline La Merced & 11,48 & 870 & 75,8 & 43 & 57 \\
\hline La Recoleta & 23,72 & 697 & 29,4 & 57 & 43 \\
\hline Sena & 26,10 & 1.641 & 62,9 & 63 & 37 \\
\hline La Tola & 17,40 & 3.174 & 182,4 & 69 & 31 \\
\hline La Victoria & 19,10 & 3.671 & 192,2 & 66 & 34 \\
\hline Panecillo & 77,69 & 4.761 & 61,3 & 69 & 31 \\
\hline San Blas & 23,67 & 3.614 & 152,7 & 68 & 22 \\
\hline San Diego & 18,35 & 2.284 & 124,5 & 78 & 29 \\
\hline San Marcos & 16,79 & 2.008 & 119,6 & 71 & 45 \\
\hline San Sebastián & 27,38 & 3.963 & 144,7 & 55 & 32 \\
\hline
\end{tabular}

Tabla 1. Abandono y Permanencia de los barrios del CHQ. (Fuente: Melissa Velástegui, 2017)

Tab. 1. Abandono y Permanencia de los barrios del CHQ. (Fuente: Melissa Velástegui, 2017) 


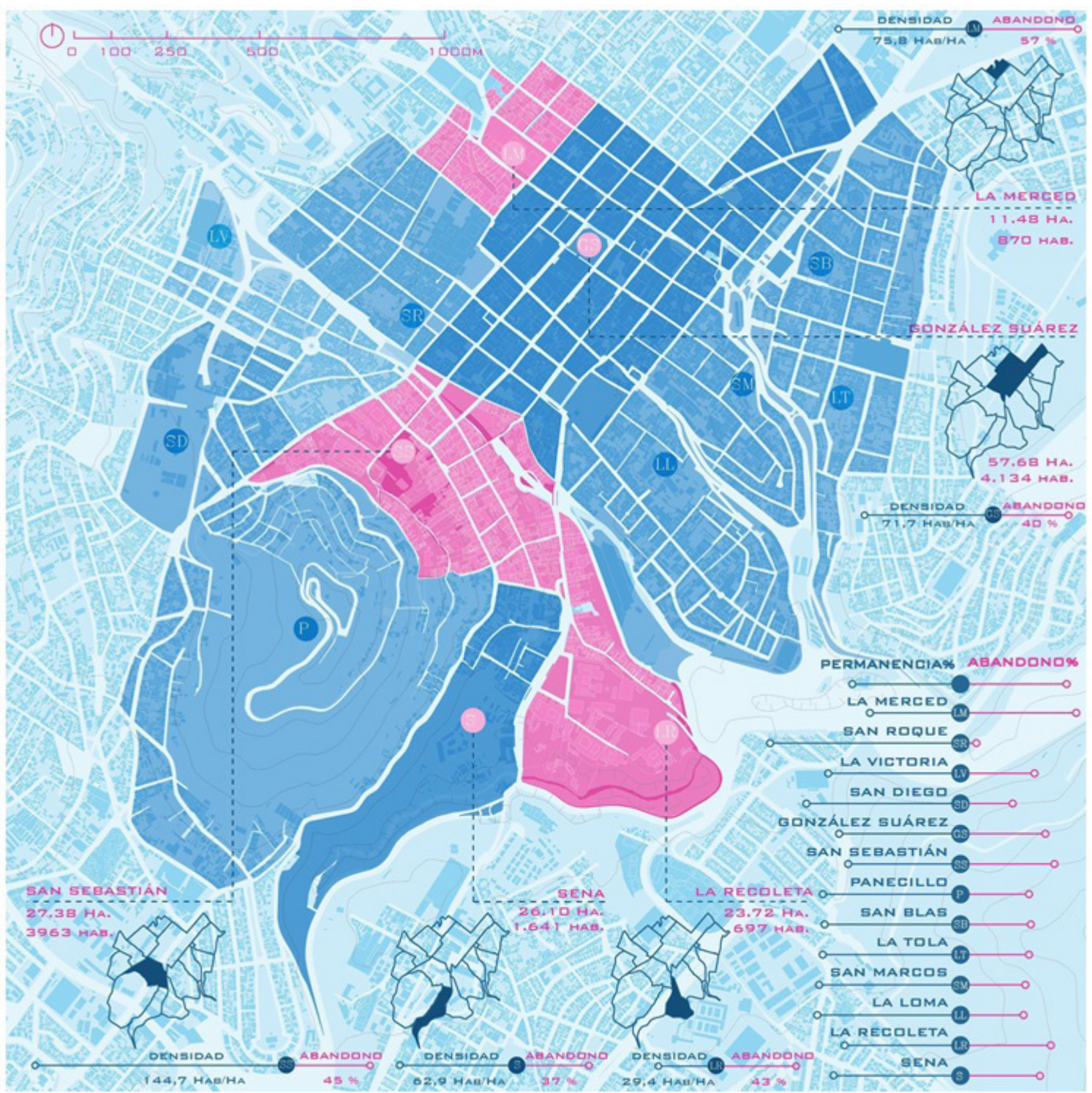

Fig. 2. Permanencia vs. abandono. (Fuente: Melissa Velástegui, 2017)

hasta la actualidad, teniendo en cuenta la densidad poblacional. En base a este estudio se encuentra que aquellos barrios que presentan un mayor porcentaje de abandono son: La Merced (57\%), San Sebastián (45\%), La Recoleta (43\%), La Gonzáles Suárez (40\%) y Sena (37\%) (Instituto Nacional de Estadísticas y Censos, 2010). Tabla 1.

La calidad de vida de los habitantes, las condiciones de vivienda, la falta de elementos cotidianos, la inaccesibilidad a servicios básicos y complementarios, el déficit de áreas verdes, los procesos migratorios que se han dado en las últimas décadas, los recursos y equipamientos que abastecen solamente a una población flotante, inciden en la densidad poblacional actual del CHQ. (Instituto Metropolitano de Patrimonio, 2017); esto ha supuesto la pérdida del carácter residencial del lugar que actualmente se ve inmerso en un proceso de degradación espacial, deterioro y tugurización, la población es expulsada mientras crecen las funciones comerciales y administrativas, dejando de lado a los habitantes del sector y reforzando la condición de abandono en el núcleo urbano consolidado. Figura 2.

\section{El uso de suelo, déficit de equipamientos residenciales y subutilización de viviendas}

El CHQ es sede política del Ecuador y del Distrito por lo que está dotado de una gran 
cantidad de instituciones públicas, entre las principales constan, la Presidencia del Ecuador y el Municipio Metropolitano de Quito.

A partir de que el sector, en el año de 1978 fuese catalogado como Patrimonio Cultural de la humanidad, la cantidad de equipamientos de carácter comercial y turístico han incrementado considerablemente, convirtiendo al turismo en una de las principales actividades económicas del lugar. En el caso de los equipamientos enfocados en los residentes, el sector presenta

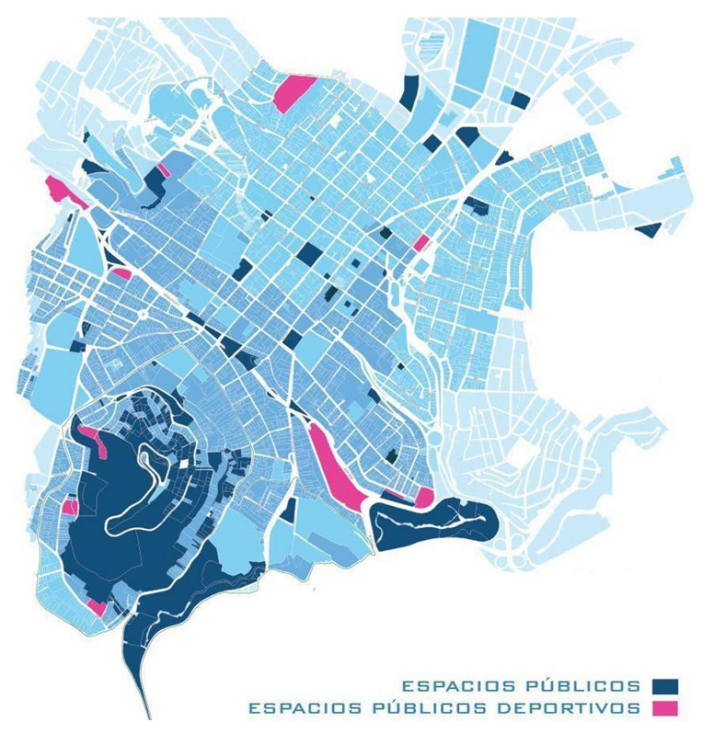

Fig. 3. Mapa de espacios públicos cívicos/religiosos vs equipamientos deportivos. (Fuente: Rafael Trujillo, 2016)

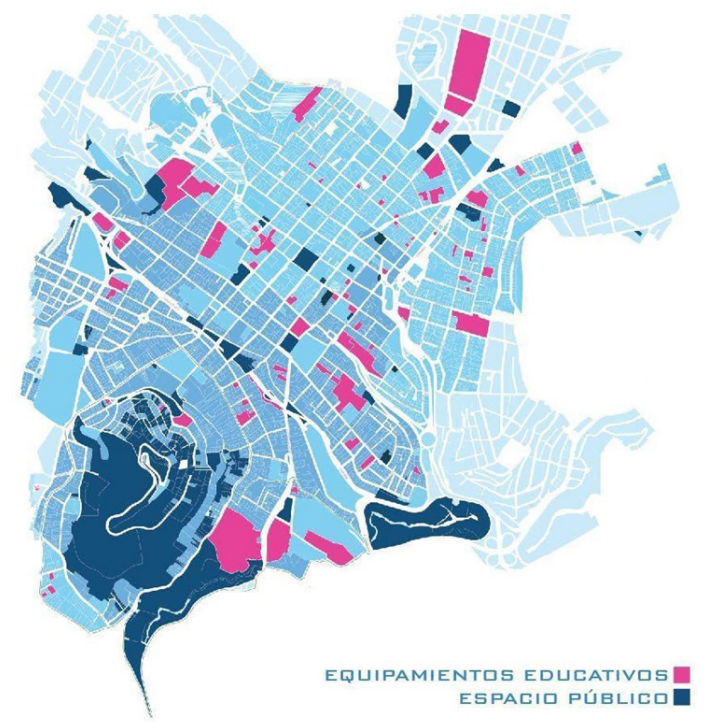

Fig. 4. Mapa de espacios públicos cívicos/religiosos vs equipamientos educativos. (Fuente: Rafael Trujillo, 2016) un déficit de $36.900 \mathrm{~m} 2$ en equipamientos deportivos y recreativos, un déficit de 13.965 $\mathrm{m} 2$ en equipamientos de salud y un exceso de $113.000 \mathrm{~m} 2$ de equipamientos educativos. Además las plazas y los espacios públicos son principalmente de carácter cívico o religioso. Figura 3 y 4.

Los equipamientos que conforman el CHQ abastecen en gran medida a una población flotante; por lo tanto no contribuyen al bienestar de los habitantes del sector. De esta manera, el $94 \%$ de usuarios de estos equipamientos son extranjeros y solo el $6 \%$ nacionales, de los cuales menos del 3\% corresponde al mismo sector (Instituto Metropolitano de Patrimonio, 2017).

En cuanto al uso de suelos, el uso residencial representa el $70 \%$ del total de infraestructuras (3272 infraestructuras) pero solamente alrededor del 48\% (2244 infraestructuras) son utilizadas como viviendas, el resto se encuentran subutilizadas como bodegas de comercio o en muy mal estado y abandonadas (MDMQ 2015). Figura 5.

\section{Morfología urbana, espacios subutilizados - espacios de oportunidad}

El Centro histórico de Quito presenta un alto

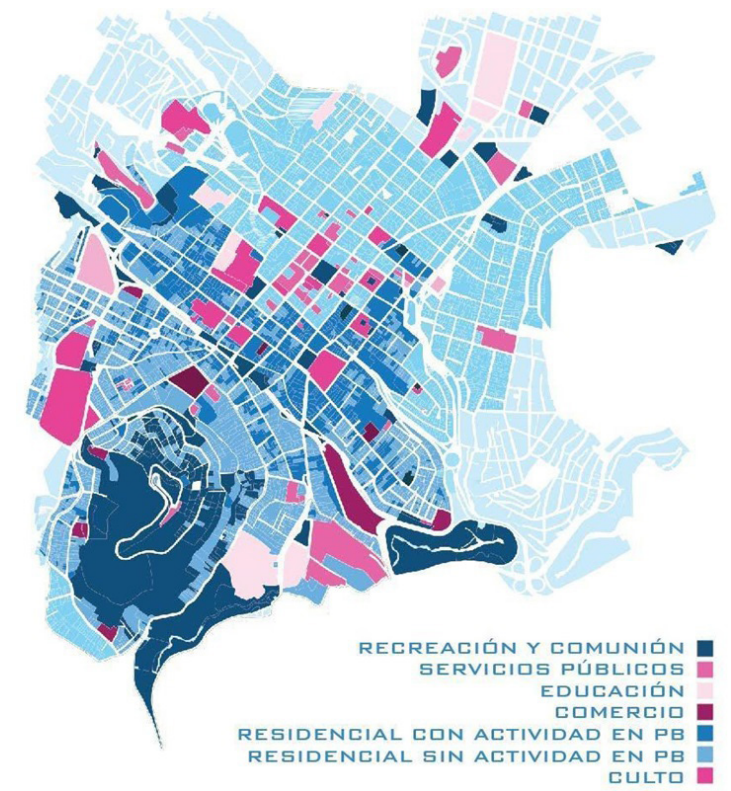

Fig. 5. Mapa de uso de suelos CHQ. Fuente: (Rafael Trujillo, 2016) 


\section{ESTADO INFRAESTRUCTURA}

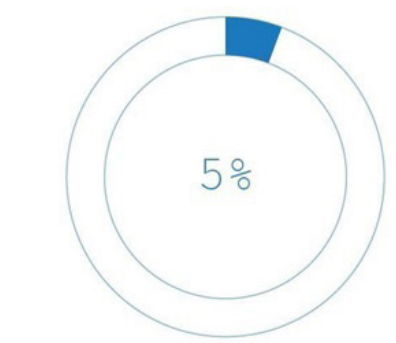

DE INFRAESTRUCTURAS EN BUEN ESTADD

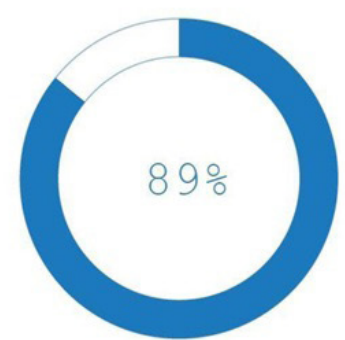

DE INFRAESTRUCTURAS EN REGULAR ESTADD

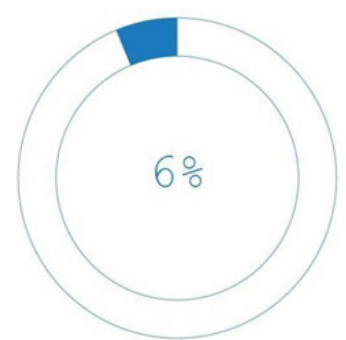

DE INFRAESTRUCTURAS EN MAL ESTADI

Fig. 6. Infogramas del estado de infraestructuras. (Fuente: Rafael Trujillo, 2016)

porcentaje de infraestructuras subutilizadas y abandonadas, las cuales podrían aprovecharse como espacios de oportunidad para futuras intervenciones.

Una de las principales consecuencias de la baja densidad poblacional es el abandono

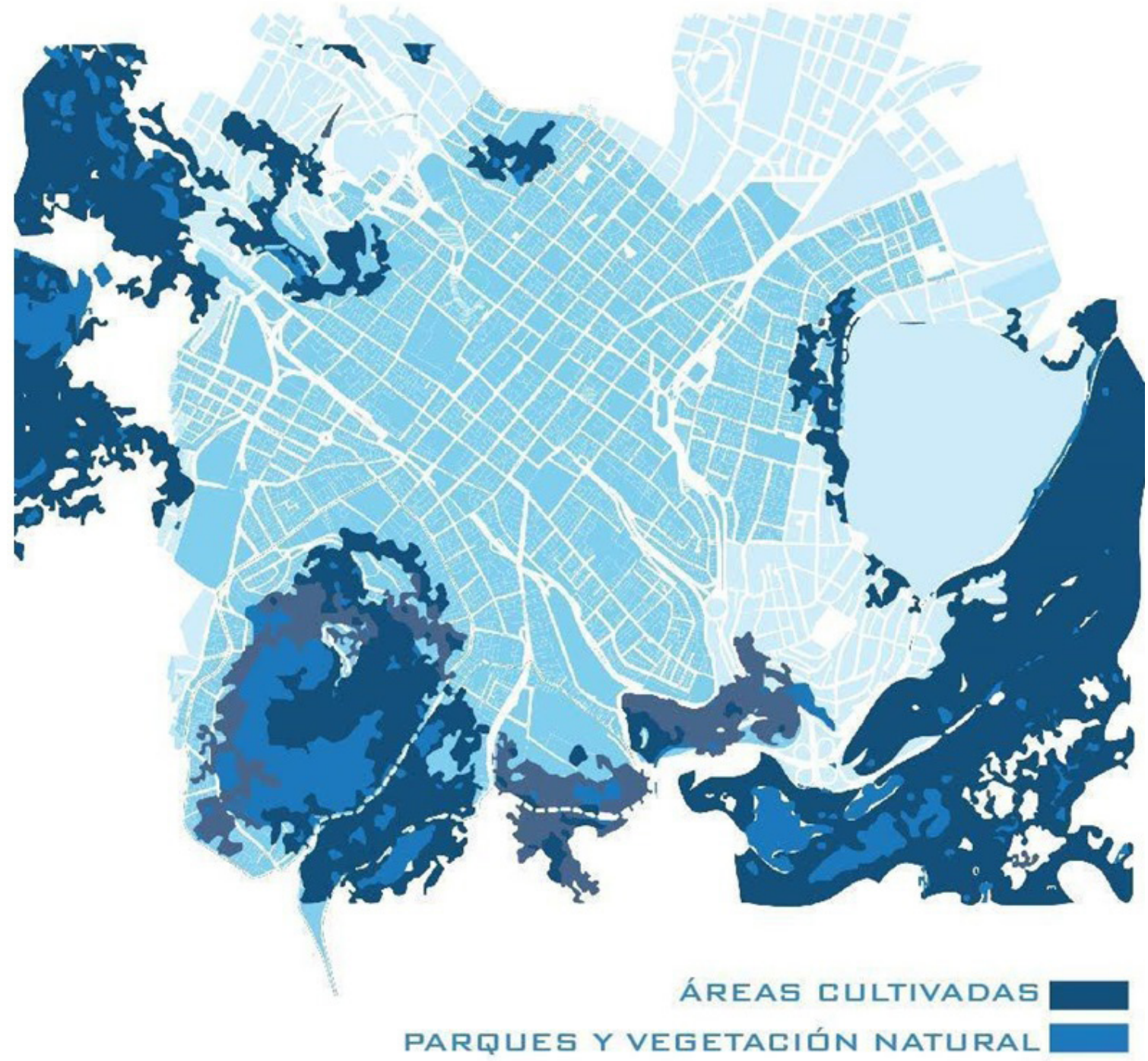

Fig. 7. Mapa de áreas verdes. (Fuente: Rafael Trujillo, 2016 
y la subutilización de las infraestructuras, las cuales se encuentran deterioradas, generando una gran problemática para los habitantes del sector, así como la afectación a su valor patrimonial. Cuantitativamente solamente el $5 \%$ de las infraestructuras se encuentran en buen estado, el $89 \%$ en un estado regular y el $6 \%$ en muy mal estado (MDMQ 2015). Figura 6.

Actualmente el CHQ se encuentra totalmente consolidado, y sus principales áreas verdes se encuentran ubicadas en sus periferias; por lo tanto, los barrios que lo conforman cuentan con pocas áreas de este tipo. Las plazas y parques tienen un enfoque turístico y comercial convirtiéndolos en espacios efímeros y de paso para sus residentes, imposibilitando la realización de actividades cotidianas. Además, las grandes manchas verdes del CHQ se encuentran subutilizadas y en mal estado, por lo que no aportan a la imagen urbana del sector y corresponden en su mayoría a elevaciones tipo lomas como el Panecillo o quebradas como la del Censo cuya superficie se destina a cultivos o vegetación nativa en mal estado. A partir de un análisis urbano del CHQ se establece que sólo existen 10.6 ha. de áreas verdes, lo que signfica que no se alcanza siqueira $\operatorname{los} 3 \mathrm{~m} 2$ por habitante. Esto demuestta que existe un déficit de 26 ha. para alcanzar el mínimo establecido por la OMS de $9 \mathrm{~m} 2$ por habitante (Instituto Metropolitano de Patrimonio, 2017). Figura 7.

\section{Áreas verdes y espacios públicos}

Actualmente el CHQ se encuentra totalmente consolidado, y sus principales áreas verdes se encuentran ubicadas en sus periferias; por lo tanto, los barrios que lo conforman cuentan con pocas áreas de este tipo. Las plazas y parques tienen un enfoque turístico y comercial convirtiéndolos en espacios efímeros y de paso para sus residentes, imposibilitando la realización de actividades cotidianas. Además, las grandes manchas verdes del CHQ se encuentran subutilizadas y en mal estado, por lo que no aportan a la imagen urbana del sector y corresponden en su mayoría a elevaciones tipo lomas como el Panecillo o quebradas como la del Censo cuya superficie se destina a cultivos o vegetación nativa en mal estado.

A partir de un análisis urbano del CHQ se establece que sólo existen 10.6 ha. de áreas verdes, lo que signfica que no se alcanza siqueira $\operatorname{los} 3 \mathrm{~m} 2$ por habitante. Esto demuestta que existe un déficit de 26 ha. para alcanzar el mínimo establecido por la OMS de $9 \mathrm{~m} 2$ por habitante (Instituto Metropolitano de Patrimonio, 2017). Figura 7.

\section{Problemáticas y actualidad}

Según el Instituto de la Ciudad de Quito en el Distrito Metropolitano, el perfil de crecimiento demográfico para el año 2025 se mantendrá en las zonas norte, sur y valles (Municipio del Distrito Metropolitano de Quito, 2015), sin ser éste el caso del CHQ, que presenta un índice de decrecimiento poblacional bastante alto (Instituto Nacional de Estadísticas y Censos, 2010).

A partir de la declaración de Quito como Patrimonio de la Humanidad por la UNESCO empezaron a surgir los planes especiales para el CHQ como principal representante de dicho patrimonio. Sin embargo, el énfasis de todos estos planes estaban en potencializarlo como un punto turístico de la ciudad, por lo tanto, todos los proyectos se han volcado en crear equipamientos destinados a la población flotante, principalmente extranjera, y poco se ha tratado de los habitantes del barrio. A partir de este momento los dueños de los inmuebles inventariados se vieron imposibilitados de rehabilitarlos de acuerdo a las nuevas normativas patrimoniales y muchos de ellos empezaron el proceso de abandono y posterior degradación. Las edificaciones al no encontrarse en condiciones óptimas para su uso han sido utilizadas como bodegas de los comercios aledaños.

Por citar un ejemplo, el Plan Especial del Centro Histórico del año 2003 proyectaba para el año 2010 una población de 75.000 habitantes, al comprobar con los datos oficiales de dicho año, la población tendió nuevamente a decrecer y apenas alcanzó los 49.384 habitantes. Nuevamente, las estrategias descritas en este plan no contemplaron de forma clara la intervención para que la población residente permanezca como tal. La mayoría de 
los ámbitos tratados se enfocaron nuevamente en el inventario e intervención del patrimonio edificado.

Otro ejemplo está en el proyecto especial que se realizó para rescatar la calle $\mathrm{La}$ Ronda en el año 2007. La propuesta estaba enfocada en la rehabilitación de esta icónica calle para convertirla en punto de encuentro de los habitantes del barrio. Por la falta de especificidad en el proyecto, La Ronda, actualmente, es uno de los principales atractivos vespertinos y nocturnos del CHQ. Los comercios se destinaron a la venta de artesanías para turistas. Los cafés y restaurantes, por sus elevados costos tampoco son para el consumo de los vecinos, provocando que actualmente, durante las mañanas de días ordinarios la calle pase principalmente abandonada y con los comercios parcialmente cerrados y que tenga una activación a partir de las $18 \mathrm{~h} 00$ y por la noche desde los días jueves.

Las diferentes alcaldías tampoco han logrado poner en marcha planes efectivos para evitar y controlar problemas sociales que han atacado al CHQ. A pesar de que el 70\% del total de infraestructuras tienen un uso de suelo residencial, únicamente el $48 \%$ del total de residencias tienen un uso de suelo adecuado, el resto se encuentran subutilizadas como consecuencia de la actividad turística que predomina en el núcleo urbano. Estas viviendas rompen con el tejido al convertirse en vacíos que generan problemas sociales como la inseguridad, delincuencia, prostitución, drogadicción y trabajo infantil. Otro aspecto que rompe el tejido urbano es el enfoque que tienen las principales actividades que se desarrollan en el Centro que son relacionadas nuevamente al turismo, comercio formal e informal y políticas-administrativas. Ambos aspectos espaciales y funcionales dejan de lado a los residentes del sector y refuerzan la condición de abandono en el núcleo urbano consolidado.

El impacto social y económico del turismo marcó fuertemente a la sociedad quiteña y a los mismos residentes o propietarios de las viviendas del Centro que han visto a sus viviendas como una oportunidad de inversión con fines comerciales o turísticos, pero no como un lugar para vivir. Con el paso del tiempo la subutilización de las residencias en bodegas o locales comerciales han deteriorado su estructura, hasta el punto de que muchas de ellas se encuentran abandonadas y otras que ya han colapsado.

\section{Conclusiones}

El Centro Histórico de Quito se ha convertido en un espacio degradado, gran parte de su población es de un estrato económico mediobajo y ocupan en mayor proporción las áreas periféricas. Actualmente, el CHQ ha presentado un fenómeno de tugurización en varios de los barrios que lo conforman. Los espacios residenciales subutilizados han sido ocupados muchas veces a modo de invasiones, deteriorando aún más el patrimonio del núcleo consolidado.

Los problemas de seguridad, accesibilidad y movilidad, el deterioro espacial y del paisaje urbano, sumados al déficit de equipamientos, servicios y áreas verdes, han determinado a personas de bajos recursos en situación de desarraigo y vulnerabilidad social, como el usuario del CHQ, quienes no han logrado comprender las características geográficas ni las relaciones con el contexto y carecen de una identidad histórica y cultural.

El desplazamiento de la población residente ha dado lugar a la ocupación de otros usos de menor impacto, lo que ha contribuido al alto índice de inseguridad. Todos estos factores contribuyen al proceso de decrecimiento poblacional del lugar que actúa de manera antagónica con respecto al resto de la ciudad, menisfestándose claramente en los bajos índices de densidad poblacional.

La organización política deficiente del DMQ, además de la carencia de regulaciones que respondan a las problemáticas actuales de la ciudad, ha contribuido al fenómeno de abandono del CHQ. A pesar de los diversos planes que se han establecido en los últimos años, el sector sigue presentando serios problemas estructurales, funcionales $\mathrm{y}$ ambientales. La tenencia del suelo, la ocupación informal, la degradación del espacio público y el déficit de equipamientos, son factores que obligan a plantear una intervención integral, para de esta manera frenar la problemática de 
un núcleo urbano consolidado que funciona a modo de "ciudad dispersa" por el continuo abandono.

El resultado es la percepción urbana de un centro histórico aparentemente activo por el dinamismo del turismo y el comercio, pero que realmente hacia su interior se encuentra abandonado y cada vez con menos residentes.

\section{Referencias}

Achig, L. (1983). El proceso urbano de Quito. Quito: Centro de Investigaciones CIUDAD

Andrade, R., Karina, B., Checa, G., Díaz, G., Fernández, C., Luis, G., Picconi, R. (1991). Centro Histórico de Quito. La Vivienda. Quito: TRAMA.

Carrión, F. (1990) "Centro histórico de Quito: notas para el desarrollo de una política urbana alternativa”. Serie Quito 01. Centro Histórico de Quito. Problemática y perspectivas. Quito: Fundación TRAMA/ AECID

Carrión, F. (1983). La renovación urbana en Quito. Quito: Centro de Investigaciones CIUDAD

Carrión, F. (2001). Centros Históricos de América Latina y el Caribe. Quito: UNESCO.

Fernando Carrión y Jaime Erazo Espinosa. 2013. "La forma urbana de Quito: una historia de centros y periferias". Bulletin de l'Institut français d'études andines 41 (3): doi : $10.4000 /$ bifea.361

Inés Del Pino. 2009. “Centro Histórico de Quito. Una centralidad urbana en transformación hacia el turismo. 2001-2008". Tesis de Maestría. Quito: FLACSO

Instituto Metropolitano del Patrimonio, Agencia de Ecología Urbana de Barcelona. (2015). "Sistema de Espacio Público y Movilidad en la Ciudad de Quito. Revitalización del Centro Histórico de Quito". Quito: IMP.

Instituto Nacional de Estadísticas y Censos. (12 de Junio de 2008). Recuperado el 17 de Diciembre de 2017, de http://www. ecuadorencifras.gob.ec/base-de-datoscenso-de-poblacion-y-vivienda/

Instituto Nacional de Estadísticas y Censos. (2010). Ecuador en cifras. Recuperado el 19 de Octubre de 2017, de http://www. ecuadorencifras.gob.ec/

Ministerio de Desarrollo Urbano y Vivienda. (2015). Revitalización del Centro Histótico. Quito: Subsecretaría de Hábitat y Asentamientos Humanos.

Municipio del Distrito Metropolitano de Quito. (2015). Diagnóstico Estratégico. Eje Terrotirial. Quito

Natalia Suárez. (2013). "Pérdida de población en el Centro Histórico de Quito: un análisis desde la incidencia de las políticas de vivienda". Tesis de Maestría. Quito: FLACSO

Quito, M. d. (2003). Plan Especial del Centro Histórico. Quito.

Secretaría de Territorio Hábitat y Vivienda. (2012). Plan de Ordenamiento Territorial 2012-2022. Quito. 